\title{
Major challenges in substance use research in Canada in 2019
}

\author{
Bundit Sornpaisarn ${ }^{1-3}$, Farihah Ali ${ }^{1}$, Tara Elton-Marshall ${ }^{2,4,5}$, Sameer Imtiaz ${ }^{1}$, Charlotte Probst $^{1}$, Sarnti Sornpaisarn ${ }^{6}$ \\ and Jürgen Rehm ${ }^{1,2,7-11}$ \\ ${ }^{1}$ Institute for Mental Health Policy Research, Centre for Addiction and Mental Health (CAMH), Toronto, Canada \\ ${ }^{2}$ Dalla Lana School of Public Health, University of Toronto, Canada \\ ${ }^{3}$ Faculty of Public Health, Mahidol University, Thailand \\ ${ }^{4}$ Institute for Mental Health Policy Research, Centre for Addiction and Mental Health (CAMH), London, Ontario, Canada \\ ${ }^{5}$ Department of Epidemiology and Biostatistics, Schulich School of Medicine and Dentistry, Western University, London, Ontario, Canada \\ ${ }^{6}$ Faculty of Health Science, McMaster University, Hamilton, Ontario, Canada \\ ${ }^{7}$ Campbell Family Mental Health Research Institute, CAMH, Toronto, Ontario, Canada \\ ${ }^{8}$ Department of Psychiatry, University of Toronto, Toronto, Ontario, Canada \\ ${ }^{9}$ Institute of Medical Science, University of Toronto, Toronto, Ontario, Canada \\ ${ }^{10}$ Institute of Clinical Psychology and Psychotherapy \& Center for Clinical Epidemiology and Longitudinal Studies, Technische Universität \\ Dresden, Germany \\ ${ }^{11}$ Department of International Health Projects, Institute for Leadership and Health Management, I.M. Sechenov First Moscow State Medical \\ University, Moscow
}

\begin{abstract}
Aims: To synthesize knowledge on substance use and substance-attributable burden in Canada to determine research priorities for the next 3 to 5 years.

Methods: We searched for and analyzed the latest epidemiological estimates of substance use prevalence and attributable burden and for economic data on the costs of substance use.

Results: Based on trends over 2014-2019, opioid, alcohol, and cannabis use were identified as research priorities due to their current or anticipated future impact on health burden in Canada. Specifically, future research efforts should be directed towards: (a) reducing the number of opioid prescriptions, investing in interventions for those already addicted to opioids, preventing both the development of opioid use disorders and deaths due to overdose; (b) identifying ways to reduce hazardous and harmful drinking, particularly among those with low socioeconomic status; and (c) monitoring and evaluating the impacts of the recent policy implementations for the legalization of cannabis on various outcomes. While tobacco attributable burden has been decreasing, it is important to continue to monitor vaping use over time.
\end{abstract}

Conclusions: Substance use is a significant and increasing risk factor for burden of disease, and research efforts are necessary to reduce this burden in Canada.

\section{Introduction}

The contributions of substance use (alcohol, tobacco and illicit drugs) to the total disease and injury burden have been increasing globally over the past decades relative to other risk factors (GBD 2017 Risk Factor Collaborators, 2018). North America has been no exception to this trend. As Case and Deaton (2017) have pointed out, the US has recently been experiencing a stagnation and slight decrease in life expectancy, and alcohol and opioid use have played a major role (Case \& Deaton, 2017, 2020; J. Rehm, 2020; J. Rehm \& Probst, 2018; White, Castle, Hingson, \& Powell, 2020).
This has raised the question of whether similar trends and developments could also be seen in Canada. Accordingly, this contribution examines the health and economic impact of substance use in Canada. However, we did not only want to examine substance use trends and developments in Canada; we also looked for implications of these trends, and what kind of research in substance use would be most beneficial to shape the future, independent of the current COVID-19 pandemic (for further considerations see (Jürgen Rehm et al., 2020; Volkow, 2020).

Correspondence: Bundit Sornpaisarn, Centre for Addiction and Mental Health, 33 Russell Street, Toronto, Ontario, Canada

Email: bundit.sornpaisarn@alum.utoronto.ca; bundit.sornpaisarn@camh.ca

Financial support: The Canadian Institutes of Health Research's Institute of Neurosciences, Mental Health and Addiction (Canadian Research Initiative on Substance

Misuse Ontario Node Grant SMN-13950).

Declaration of interest: None

Keywords: substance, illicit drugs, review, research, Canada 


\section{Methods}

After a systematic search for reviews on related topics yielded no results (see Appendix 1 for search terms used), two main search strategies were employed to assess the impact of substance use on health and economic indicators in Canada. First, for epidemiological data on burden of disease attributable to various risk factors, we relied on the last iteration of the Global Burden of Disease study (GBD 2017 Risk Factor Collaborators, 2018; Institute for Health Metrics and Evaluation, 2018). Second, we searched recent publications by the Canadian Institute for Health Information, Health Canada, Statistics Canada, and other relevant Canadian institutions for research on substance use.

\section{Results}

Substance Use is a Significant Contributor to Burden of Disease in Canada

Table 1

Burden of Disease Attributable to Alcohol, Tobacco and Illicit Drugs in Main Indicators for 2017: Death, Years of Life Lost (YLLs), and Disability-Adjusted Life Years (DALYs) per 100,000 Population

\begin{tabular}{|c|c|c|c|}
\hline Substance and Region & Deaths & YLLs & DALYs \\
\hline \multicolumn{4}{|c|}{ Global } \\
\hline Alcohol & 37.2 & $1,147.8$ & $1,413.1$ \\
\hline Tobacco & 106.0 & $2,294.3$ & $2,792.8$ \\
\hline Illicit drugs & 7.7 & 271.2 & 545.2 \\
\hline $\begin{array}{l}\text { Total (assuming 10\% } \\
\text { overlap) }\end{array}$ & 135.8 & $3,341.9$ & $4,276.1$ \\
\hline Attributable fraction & $30 \%$ & $27 \%$ & $27 \%$ \\
\hline \multicolumn{4}{|c|}{ North America High-Income } \\
\hline Alcohol & 23.9 & 921.0 & $1,246.3$ \\
\hline Tobacco & 136.3 & $2,533.6$ & $3,384.7$ \\
\hline Illicit drugs & 30.3 & $1,193.7$ & $1,957.1$ \\
\hline $\begin{array}{l}\text { Total (assuming 10\% } \\
\text { overlap) }\end{array}$ & 171.4 & $4,183.4$ & $5,929.3$ \\
\hline Attributable fraction & $34 \%$ & $45 \%$ & $43 \%$ \\
\hline \multicolumn{4}{|c|}{ Canada } \\
\hline Alcohol & 14.5 & 612.5 & 865.2 \\
\hline Tobacco & 142.7 & $2,470.1$ & $3,384.3$ \\
\hline Illicit drugs & 11.9 & 424.4 & 927.6 \\
\hline $\begin{array}{l}\text { Total (assuming } 10 \% \\
\text { overlap) }\end{array}$ & 152.2 & 3156.4 & 4659.4 \\
\hline Attributable fraction & $35 \%$ & $45 \%$ & $41 \%$ \\
\hline
\end{tabular}

Source: Institute for Health Metrics and Evaluation

Substance use is a major and - compared to other factors increasing risk factor for burden of disease $(\mathrm{BoD})$ globally and in high-income countries such as Canada. Table 1 provides an overview of the burden of substance use attributable to alcohol, tobacco and illicit drugs according to important BoD indicators in 2017, based on the Institute for Health Metrics and Evaluation. Overall, in Canada, substance use was responsible for $35 \%$ of all deaths, $45 \%$ of all years of life lost (YLLs), and $41 \%$ of all BoD, as expressed in disability-adjusted life years (DALYs). All calculations for overall BoD attributable to substance use assume a $10 \%$ overlap between substances (J. Rehm, Manthey, Shield, \& Ferreira-Borges, 2019).
In Canada, tobacco, drug, and alcohol use were ranked first, eighth and ninth, respectively, among the top 10 risk factors contributing to DALYs in 2017. Furthermore, drug and alcohol use were among the fastest-growing risk factors in terms of percentage increase of DALYs from 2007 to 2017. Drug use was ranked first, and alcohol use was ranked third with $31.5 \%$ and $18.4 \%$ increases in DALYs, respectively, during this time, while tobacco-attributable DALYs decreased by $0.7 \%$ (Institute for Health Metrics and Evaluation, 2018). Moreover, in 2017-2018, there were 156,108 hospitalizations which were $100 \%$ attributable to substance use; more than for heart attacks and strokes combined. Among these hospitalizations, the highest numbers were caused by alcohol $(82,740,53.0 \%)$, cannabis $(23,410,15.0 \%)$, opioids $(19,279,12.3 \%)$, other stimulants $(17,479,11.2 \%)$, and cocaine $(12,203,7.8 \%)$ (Canadian Institute for Health Information, 2019)). In short, drug and alcohol use contribute a significant $\mathrm{BoD}$ to Canada and their relative impacts have been increasing. Meanwhile, although still high, the burden caused by tobacco has been declining.

Substance use disorders are a significant contributor to substance-related burden in Canada (Table 2). In 2017, the 12-month prevalence of substance use disorders was 3,342 per 100,000 population, which caused 989 DALYs per 100,000 population. Substances that had the highest prevalence of respective substance use disorders were alcohol, followed by opioids, and then cannabis. Substances that contributed the top three burdens in terms of DALYs were opioids, alcohol, and cocaine, respectively (Global Burden of Disease Collaborative Network, 2018).

Table 2

The Prevalence of substance use disorders and their attributable DALYs, by Type of Substance, in 2017

\begin{tabular}{lcc}
\hline $\begin{array}{l}\text { Type of } \\
\text { Substance }\end{array}$ & $\begin{array}{c}\text { Prevalence } \\
\text { (No per 100,000 } \\
\text { Popn) }\end{array}$ & $\begin{array}{c}\text { DALYs } \\
\text { (DALYs per } \\
\mathbf{1 0 0 , 0 0 0} \text { Popn) }\end{array}$ \\
\hline Alcohol & 1,492 & 256 \\
Opioids & 953 & 551 \\
Cannabis & 617 & 18 \\
Cocaine & 261 & 54 \\
Amphetamine & 49 & 14 \\
All types & 3,342 & 989 \\
\hline
\end{tabular}

Source: Global Burden of Disease Collaborative Network, 2018

\section{Substance Use Affects Life Expectancy in North America}

In North America, there are signs of an increasing impact of substance use on public health (GBD 2017 Risk Factor Collaborators, 2018; J. Rehm, Anderson, Fischer, Gual, \& Room, 2016) including, but not limited to, the impact on life expectancy in the US (Case \& Deaton, 2015, 2017; J. Rehm, 2020; J. Rehm \& Probst, 2018), mainly attributable to opioid and alcohol use.

In Canada, life expectancy was increasing up until 2016, albeit with a decreasing slope, but between 2016 and 2018 it stagnated (Statistics Canada, 2020b). Alcohol, and especially opioids, contributed significantly to this development. Among younger adults in Canada, alcohol and drug use were the most impactful risk factor for mortality, 
contributing to $25 \%$ of deaths in 2016 , up from less than $20 \%$ in 1990 (Probst \& Rehm, 2018). Recently, opioid overdose deaths have sharply increased (from 3,017 deaths in 2016 to 4,100 and 4,460 in 2017 and 2018; this accounted for 8.4, 11.2 , and 12.0 deaths per 100,000 population, per year respectively) (Public Health Agency Canada, 2019) and deaths and hospitalizations attributable to alcohol have also increased to record levels (Probst \& Rehm, 2018; Public Health Agency Canada, 2018b).

\section{Alcohol and Drug Use Impose a High Economic Cost to Canadian Society}

The Canadian Substance Use Costs and Harms Scientific Working Group conducted a study estimating the economic costs and harms of substance use in Canada for the years 2007 to 2014. The following cost categories were separated: lost productivity ( $\$ 15.7$ billion), healthcare ( $\$ 11.1$ billion), criminal justice ( $\$ 9.0$ billion), and other indirect costs $(\$ 2.7$ billion). Overall, the cost of substance use was $\$ 38.4$ billion in Canada in 2014, translating into $\$ 1,081$ per capita
(Canadian Substance Use Costs and Harms Scientific Working Group, 2018). The study also demonstrated that between 2007 and 2014, the costs per capita attributable to substance use increased by $5.5 \%$, adjusted for inflation. Table 3 shows that alcohol, tobacco, opioids, and cannabis were the leading four substances that contributed the most to the cost of substance use, respectively. Cannabis, alcohol, CNS depressants, and tobacco were the top four substances that had the highest increase in cost per person between 2007 and 2014, respectively. Substance use caused a significant economic burden to Canadian society and most of these costs have increased over the past years. At the same time, the net income received by the federal government from liquor authorities and total taxes and other revenues totaled $\$ 12.2$ billion in the fiscal year of 2017 (Statistics Canada, 2020a). Tobacco tax revenue received by Canadian governments in the fiscal year of 2018 was $\$ 8.3$ billion (Physicians for a Smoke-Free Canada, 2019). Costs for both substances still exceeded the incomes.

Table 3

Overall Costs of Substance Use in Canada in 2014 and Trends in Economic Costs from 2007 to 2014

\begin{tabular}{|c|c|c|c|c|c|}
\hline \multirow[t]{2}{*}{ Type of Substance } & \multicolumn{2}{|c|}{$\begin{array}{l}\text { Overall Cost in } 2014 \\
\end{array}$} & \multicolumn{3}{|c|}{ Cost per Person } \\
\hline & $\begin{array}{l}\text { Overall Costs } \\
\text { (Billion) }\end{array}$ & $\begin{array}{c}\% \text { of Total Overall } \\
\text { Costs }\end{array}$ & $\begin{array}{c}2007 \\
\text { (\$ per } \\
\text { Person) }\end{array}$ & $\begin{array}{c}2014 \\
\text { (\$ per } \\
\text { Person) }\end{array}$ & $\begin{array}{c}\text { Change } \\
(\%)\end{array}$ \\
\hline Alcohol use & 14.6 & 38.1 & 369 & 412 & 11.6 \\
\hline Tobacco use & 12.0 & 31.2 & 315 & 337 & 6.8 \\
\hline Opioid use & 3.5 & 9.1 & 97 & 98 & 0.9 \\
\hline Cannabis use & 2.8 & 7.3 & 67 & 70 & 19.1 \\
\hline Cocaine & 2.2 & 5.8 & 20 & 16 & -17.9 \\
\hline CNS depressants & 1.5 & 4.0 & 39 & 43 & 10.0 \\
\hline Other substances & 0.6 & 1.5 & 84 & 63 & -24.6 \\
\hline
\end{tabular}

Source: Canadian Substance Use Costs and Harms Scientific Working Group. (2018)

\section{Summary of Areas of Substance Use Which Need Research Prioritization in Canada}

Opioid use.

The increasing number of fatalities involving opioids represents a growing public health crisis. More than 14,700 deaths in Canada between January 2016 and September 2019 were attributable to opioids, with the trend still increasing. Of the deaths in 2019, 94\% were the result of accidental overdoses, of which more than three-quarters (78\%) involved fentanyl and fentanyl-related substances (Special Advisory Committee on the Epidemic of Opioid Overdoses, 2020). Among OD deaths with completed investigations in 2019, 67\% involved only non-pharmaceutical opioids, $9 \%$ involved both pharmaceutical and non-pharmaceutical opioids, and $19 \%$ involved only pharmaceutical opioids (i.e., oxycodone, hydrocodone, morphine) (Special Advisory Committee on the Epidemic of Opioid Overdoses, 2020). In 2019 , the vast majority of opioid ODs occurred among males $(75 \%)$ and the largest share occurred among adults aged 30 to 39 years old $(27 \%)$.
Rates of harm due to opioid overdose continue to rise across Canada. The number of hospitalizations attributable to opioid overdoses between January 2016 and September 2019 equaled 19,490. In 2018, opioid overdoses caused the hospitalization of 15 Canadians every day. In total, there were 5,349 hospitalizations due to opioid overdoses in Canada in 2018 (accounting for an age-standardized rate of 18.6 per 100,000 population (Special Advisory Committee on the Epidemic of Opioid Overdoses, 2020).

The national rate for hospitalizations for opioid overdoses in 2018 was up 8\% from 2016 and 27\% from 2013 (Canadian Institute for Health Information, 2018b). Opioid overdoses affect medium-sized and suburban communities across Canada more than urban centers. Between 2013 and 2017, the fastest-growing rate of hospitalizations due to opioid overdose was found in younger adults aged 25-44 years (with an increase of 62\%), followed by adolescents aged 1524 years (with a 53\% increase). Over the four-year span, the greatest increase in the male population was in the age group 25-44 years, whereas in the female population the greatest increase was in the age group 15-24 years. Another 
significant group is that of pregnant women who use opioids; statistics show that there was a $20 \%$ increase in the rate of hospitalizations for neonatal withdrawal symptoms between 2013 (4.3 per 1,000 in-hospital live births) and 2017 (5.2 per 1,000 in-hospital live births) (Canadian Institute for Health Information, 2018c).

Although Statistics Canada has started to harmonize OD data, major gaps still exist in data reporting for deaths, hospitalizations, and Emergency Department (ED) visits. In addition, while research and interventions focus on treatments for opioid use disorders and avoiding ODs, root causes for these problems are not being addressed such as by changing the healthcare system to markedly reduce the number of opioid prescriptions written by medical professionals (Fischer, Rehm, \& Tyndall, 2016), especially for patients at risk (Ladapo et al., 2018), as well as by protecting people from the current supplies of toxic street drugs (Fischer, Pang, \& Tyndall, 2019).

While an unprecedented number of research projects has have been initiated to address the current opioid crisis, including the Emerging Health Threat projects created by the Canadian Research Initiative in Substance Misuse (CRISM) (Canadian Research Initiative in Substance Misuse (CRISM), 2015), significant knowledge gaps still exist. Thus, while it is clear that prescription opioid use has been one of the major pathways to opioid addiction and ODs (Imtiaz, Shield, Fischer, \& Rehm, 2014), the best ways to address non-medical use of opioids is unclear, and more Canada-specific research is needed. Different solutions in different provinces may also need to be considered. Furthermore, whereas the take-home Naloxone, opioidagonist therapy, and overdose prevention services based on a modeling study have been successful interventions in reducing opioid ODs in British Columbia (Irvine et al.), it is necessary to develop a multi-pronged approach to address both the needs of those who are already addicted to opioids as well as to prevent the development of future opioid use disorders and ODs. Economic studies to determine the best mix of different measures to treat opioid addiction are necessary. Such studies exist for other substance use areas (Chisholm, Doran, Shibuya, \& Rehm, 2006) but not for the area of opioid research.

\section{Alcohol.}

Alcohol use has profound impacts on chronic and acute health in Canada (Public Health Agency Canada, 2016; J. Rehm et al., 2017). Overall, alcohol consumption is linked to more than 200 different diseases, conditions, and types of injuries (J. Rehm et al., 2009). A systematic review of 255 reviews and meta-analyses confirmed the importance of alcohol use as a risk factor for diseases and injuries (J. Rehm et al., 2017). These conditions include more than 40 ICD-10 three-digit categories which are either wholly or partially attributable to alcohol and showed a linear relationship between the volume of alcohol use and the risk of disease or death. Previous studies showed that ischemic diseases and diabetes are exceptions since these two conditions have curvilinear relationships with alcohol use: beneficial effects of light to moderate drinking were seen in people without irregular heavy drinking occasions (or binge drinking) (J.
Rehm et al., 2017). However, the recent systematic analysis from the Global Burden of Diseases, Injuries, and Risk Factors Study (GBD) 2016 for 195 countries and territories, 1990-2016, suggests that there is no safe lower limit for alcohol drinking (GBD 2016 Alcohol Collaborators, 2018); see also Shield and Rehm (2019). The reason is that the estimated protective effects for ischemic heart disease and diabetes in women are often offset by monotonic associations with cancer (Burton \& Sheron, 2018). This finding has further implications for public health policy, and suggests that policies that reduce population-level consumption should be prioritized (Burton \& Sheron, 2018).

Adult Canadians (15 years of age and older) consumed an average of 9.1 litrers of pure alcohol per person per year in 2017 (Manthey et al., 2019). In the same year, the prevalence of current alcohol use (past 12 months) was $69 \%$ among adult Canadians (about 21.3 million) who used alcohol in the past year (Manthey et al., 2019), with a higher prevalence among men (78\%, 11.8 million) compared to women $(61 \%, 9.5$ million) (Manthey et al., 2019).

In 2017, 21\% (4.7 million) and 15\% (3.3 million) of Canadian alcohol users (aged 15 years and older who drank alcohol in the past year) exceeded Canada's Low-Risk Alcohol Drinking Guidelines for long- and short-term risks, respectively. Males' alcohol use was more problematic than females', and drinking behaviors of young adults (aged 2024 years) was more problematic than those of adults (aged 25 years and older) and adolscents (aged 15-19 years) for both long- and short-term risks (Statistics Canada, 2019).

In 2015-2016, there were more hospitalizations in Canada for $100 \%$ alcohol-attributable disease $(77,000)$ than for heart attacks $(75,000)$ (Canadian Institute for Health Information, 2017). In 2017-2018, as mentioned above, the situation was even worse (Canadian Institute for Health Information, 2019). The number of hospitalizations for harm caused by alcohol use rose to 82,740 . An average of ten patients died in the hospital every day due to substance use - most $(77 \%)$ from health complications related to alcoholism. Note: the $100 \%$ alcohol-attributable diseases include, for example, chronic alcohol use disorder, alcohol withdrawal, alcoholinduced cirrhosis of liver, alcohol-induced pancreatitis, not including alcohol-related injuries (Canadian Institute for Health Information, 2017). In 2014, alcohol contributed to 14,826 deaths in Canada whereas there were 1472 road crash deaths which involved alcohol in 2014 (Canadian Centre on Substance Use and Addiction, 2019; Lyon, Brown, Van Laar, \& Robertson, 2019).

In addition to the fact that alcohol use seems to link to more premature deaths in the US than opioid use, the following are warning signs for Canada, especially for women:

- The rate of women who died from causes linked directly to alcohol has increased by $26 \%$ since 2001 , compared with a roughly $5 \%$ increase over the same period for men (Canadian Institute for Health Information, 2018a) (see also (Public Health Agency Canada, 2018a)).

- More than 25,000 women had alcohol-related hospitalizations in 2016-2017, representing a nearly $3 \%$ increase over the previous year. By comparison, the 
increase for men was $0.6 \%$ over the same period (Canadian Institute for Health Information, 2017).

- The proportion of alcohol-attributable deaths to all deaths increased in recent years (Canadian Institute for Health Information, 2018a), again particularly for women.

Based on data from 1991 to 2006 Canadian Census Mortality and Cancer follow-up study, age-standardized mortality rates from alcohol-related causes of death in particular were clearly influenced by income (Tjepkema, Wilkins, \& Long, 2013a), education (Tjepkema, Wilkins, \& Long, 2012) and occupation (Tjepkema, Wilkins, \& Long, 2013b). Mortality rates from alcohol-related causes of death were lowest among people in the highest socioeconomic status quintile, and highest among people in the lowest quintile.

Clearly, alcohol use is one of the most overlooked risk factors in Canada and current policy development may further aggravate the situation (i.e., the implementation of lowering the minimum price of beer from approximately $\$ 1.25$ to $\$ 1.00$ for a can or bottle in Ontario) (Manthey et al., 2019). Alcohol use should be reintegrated into research priorities based on its current impact. Research priorities in the area of alcohol should cover knowledge generation to inform the government on implementing evidence-based alcohol control policies to guide the health and social service system to reduce and prevent hazardous and harmful drinking and its related health consequences, particularly for people with low socio-economic status.

\section{Cannabis.}

Based on causal impacts on cannabis use disorders, schizophrenia, lung cancer and road traffic injuries, cannabis use in Canada in 2012 was estimated to cause 287 deaths (95\% CI: 108-609); 10,533 YLLs (95\% CI: 4,760-20,833); 55,813 YLDs (95\% CI: 38,175-74,094), and 66,346 DALYs (95\% CI: 47,785-87,207) (Imtiaz et al., 2016). The cannabisattributable burden of disease was greatest among young people, and males accounted for twice the burden of females. The most prominent single cause of the cannabis-attributable burden of disease was cannabis use disorders (Imtiaz et al., 2016). In Canada, the burden caused by cannabisattributable consequences appears to occur through motor vehicle accidents and cannabis use disorders, while those caused by lung cancer and psychosis happen on a significantly smaller scale (Fischer, Imtiaz, Rudzinski, \& Rehm, 2016).

In 2017, before cannabis legalization, $15 \%$ (or 4.4 million) of Canadians adults (15 years of age and older) had consumed cannabis over the past year. Among cannabis users, about three out of four used cannabis in the past three months, and one out of four used cannabis every day or almost every day. More males (19\%, 2.7 million) used cannabis than females (11\%, 1.7 million). The prevalence of cannabis use among young adults aged 20 to 24 (33\%) was higher than among adolescents aged 15 to $19(19 \%)$ and adults aged 25 years and older (13\%) (Statistics Canada, 2019).
However, Canada's legalization of cannabis in October 2018 , together with a wide availability of medical marijuana, constitutes a unique experiment in a high-income country, which needs to be monitored as the results are not yet clear and will very much depend on the success of similar implementation in different provinces (Crepault, Rehm, \& Fischer, 2016; J. Rehm et al., 2017). For example, all provinces determine the minimum legal purchasing age for cannabis at 19 years old except for Alberta and Quebec. Many other policy interventions vary among provinces and require evaluation. These policy options include controlling the distribution of cannabis (through government or private sale); regulating its availability; influencing demand through pricing and taxation; curtailing higher-risk products and formulations; prohibiting marketing, advertising and sponsorship; displaying product information; preventing cannabis-impaired driving; enhancing access to treatment and expanding treatment options; as well as investing in education and prevention (Crepault et al., 2016). The results of these policy interventions have to be monitored and evaluated, especially the impact of heavy use/frequent use over time, the use of cannabis while operating machinery such as a car, the use of cannabis containing high levels of tetrahydrocannabinol (THC), the smoking of cannabis mixed with tobacco, and the use of cannabis in early and mid-adolescence (J. Rehm et al., 2017). If all these regulatory measures are carefully introduced based on best available evidence, with independent monitoring and surveillance, and with openness to change in case of negative consequences, Canada has a chance to become a leader as a country with evidence-driven public health policy decisionmaking (J. Rehm et al., 2017).

\section{Discussion}

Based on the above data, three areas of substance use deserve particular attention with respect to public health in Canada, and research is necessary to help shape the best interventions and policies in these areas:

1. Opioid use and resulting overdoses (ODs)

2. The increasing burden of disease resulting from alcohol use

3. Monitoring the legalization of cannabis, and its potential effects

Tobacco is not mentioned here-despite having the largest impact on the number of deaths - as the tobacco-attributable burden of disease is decreasing (Institute for Health Metrics and Evaluation, 2018). This suggests that the current collective efforts and investment put into the implementation of policies, programs and research to curtail problems caused by tobacco use are headed in a good direction and should continue to do so. Additionally, Canada has previously articulated an endgame strategy for tobacco control with clearly identified priorities for tobacco control (Dubray, Chaiton, \& Schwartz, 2019). However, it should be noted that the prevalence of vaping e-cigarettes is on the rise with most recent estimates in Canada demonstrating that lifetime use of e-cigarettes increased significantly from 8.5 to $15.4 \%$ between 2013 and 2017 among adults 15 years of age and older (Reid et al., 2019). Additionally, vaping has increased in popularity with the emergence of new vaping devices such 
as those containing nicotine salts and high nicotine concentrations (Hammond et al., 2019). Some longitudinal studies have also suggested that the use of e-cigarettes may be associated with an increased risk of subsequent cigarette smoking among adolescents (Berry et al., 2019). Given that the long-term health impacts of vaping e-cigarettes are unknown (National Academies of Sciences \& Engineering \& Medicine, Health Medicine Division, Board on Population Health and Public Health Practice, \& Committee on the Review of the Health Effects of Electronic Nicotine Delivery Systems, 2018), it is important to continue to monitor e-cigarette use over time.

\section{Funding Sources}

The authors acknowledge funding from the Canadian Institutes of Health Research's Institute of Neurosciences, Mental Health and Addiction (Canadian Research Initiative on Substance Misuse Ontario Node Grant SMN-13950)

\section{Declaration of Interests}

The authors declare that there is no conflict of interest.

\section{References}

Berry, K. M., Fetterman, J. L., Benjamin, E. J., Bhatnagar, A., Barrington-Trimis, J. L., Leventhal, A. M., \& Stokes, A. (2019). Association of electronic cigarette use with subsequent initiation of tobacco cigarettes in US youths. JAMA Network Open, 2(2), e187794-e187794.

Burton, R., \& Sheron, N. (2018). No level of alcohol consumption improves health. Lancet, 392(10152), 987988. doi:10.1016/S0140-6736(18)31571-X

Canadian Centre on Substance Use and Addiction. (2019). Canadian drug summary: Alcohol. Retrieved from https://www.ccsa.ca/sites/default/files/2019-09/CCSACanadian-Drug-Summary-Alcohol-2019-en.pdf

Canadian Institute for Health Information. (2017). Alcohol harm in Canada: Examining hospitalizations entirely caused by alcohol and strategies to reduce alcohol harm. Retrieved from https://www.cihi.ca/sites/default/files/document/reportalcohol-hospitalizations-en-web.pdf

Canadian Institute for Health Information. (2018a). Alcohol harm on the rise for Canadian women. Retrieved from https://www.cihi.ca/en/alcohol-harm-on-the-rise-forcanadian-women

Canadian Institute for Health Information. (2018b). Opioidrelated harms in Canada. Ottawa, ON: CIHI.

Canadian Institute for Health Information. (2018c). PanCanadian trends in prescribing of opioids and benzodiazepines, 2012 to 2017. Ottawa, ON: CIHI.

Canadian Institute for Health Information. (2019). Common challenges, shared priorities: measuring access to home and community care and to mental health and addictions services in Canada. Ottawa, ON: CIHI.

Canadian Research Initiative in Substance Misuse (CRISM). (2015). CRISM-ICRAS homepage. Retrieved from https://crism.ca/

Canadian Substance Use Costs and Harms Scientific Working Group. (2018). Canadian substance use costs and harms (2007-2014). Retrieved from
http://www.ccsa.ca/Resource\%20Library/CSUCHCanadian-Substance-Use-Costs-Harms-Report-2018en.pdf

Case, A., \& Deaton, A. (2015). Rising morbidity and mortality in midlife among white non-Hispanic Americans in the 21st century. Proceedings of the National Academy of Sciences of the United States of America, 112(49), doi:10.1073/pnas.1518393112.

Case, A., \& Deaton, A. (2017). Mortality and morbidity in the 21st century. Brookings Pap Econ Act, 2017, 397476. Retrieved from https://www.brookings.edu/wpcontent/uploads/2017/08/casetextsp17bpea.pdf

Case, A., \& Deaton, A. (2020). Deaths of Despair and the Future of Capitalism. Princeton, NJ: Princeton University Press.

Chisholm, D., Doran, C., Shibuya, K., \& Rehm, J. (2006). Comparative cost-effectiveness of policy instruments for reducing the global burden of alcohol, tobacco and illicit drug use. Drug and Alcohol Review, 25(6), 553-565.

Crepault, J. F., Rehm, J., \& Fischer, B. (2016). The Cannabis Policy Framework by the Centre for Addiction and Mental Health: A proposal for a public health approach to cannabis policy in Canada. International Journal of Drug Policy, 34, 1-4. doi:10.1016/j.drugpo.2016.04.013

Dubray, J., Chaiton, M., \& Schwartz, R. (2019). Tobacco endgame simulation modelling: Assessing the impact of policy changes on smoking prevalence in 2035. Special Report. Toronto, ON: Ontario Tobacco Research Unit.

Fischer, B., Imtiaz, S., Rudzinski, K., \& Rehm, J. (2016). Crude estimates of cannabis-attributable mortality and morbidity in Canada-implications for public health focused intervention priorities. Journal of Public Health, 38(1), 183-188. doi:10.1093/pubmed/fdv005

Fischer, B., Pang, M., \& Tyndall, M. (2019). The opioid death crisis in Canada: crucial lessons for public health. Lancet Public Health, 4(2), e81-e82. doi:10.1016/S2468-2667(18)30232-9

Fischer, B., Rehm, J., \& Tyndall, M. (2016). Effective Canadian policy to reduce harms from prescription opioids: learning from past failures. CMAJ: Canadian Medical Association Journal, 188(17-18), 1240.

GBD 2016 Alcohol Collaborators. (2018). Alcohol use and burden for 195 countries and territories, 1990-2016: a systematic analysis for the Global Burden of Disease Study 2016. Lancet, 392(10152), 1015-1035. doi:https://doi.org/10.1016/S0140-6736(18)31310-2

GBD 2017 Risk Factor Collaborators. (2018). Global, regional, and national comparative risk assessment of 84 behavioural, environmental and occupational, and metabolic risks or clusters of risks for 195 countries and territories, 1990-2017: a systematic analysis for the Global Burden of Disease Study 2017. Lancet, 392(10159), 1923-1994 doi:https://doi.org/10.1016/S0140-6736(18)32225-6

Global Burden of Disease Collaborative Network. (2018). Global Burden of Disease Study 2017 (GBD 2017) Results. Seattle, United States: Institute for Health Metrics and Evaluation (IHME). Retrieved from http://ghdx.healthdata.org/gbd-results-tool

Hammond, D., Reid, J. L., Rynard, V. L., Fong, G. T., Cummings, K. M., McNeill, A., . . Bansal-Travers, M. 
(2019). Prevalence of vaping and smoking among adolescents in Canada, England, and the United States: repeat national cross sectional surveys. BMJ, 365, 12219.

Imtiaz, S., Shield, K. D., Fischer, B., \& Rehm, J. (2014). Harms of prescription opioid use in the United States. Substance Abuse Treatment, Prevention and Policy, 9(1), 43.

Imtiaz, S., Shield, K. D., Roerecke, M., Cheng, J., Popova, S., Kurdyak, P., . . . Rehm, J. (2016). The burden of disease attributable to cannabis use in Canada in 2012. Addiction, 111(4), 653-662.

Institute for Health Metrics and Evaluation. (2018). Country Profile: Canada. Retrieved from http://www.healthdata.org/canada

Irvine, M. A., Kuo, M., Buxton, J., Balshaw, R., Otterstatter, M., Macdougall, L., . . . Gilbert, M. Modelling the combined impact of interventions in averting deaths during a synthetic-opioid overdose epidemic. Addiction, 114(9), 1602-1613. doi:10.1111/add.14664

Ladapo, J. A., Larochelle, M. R., Chen, A., Villalon, M. M., Vassar, S., Huang, D. Y. C., \& Mafi, J. N. (2018). Physician prescribing of opioids to patients at increased risk of overdose from benzodiazepine use in the United States. JAMA Psychiatry, 75(6), 623-630. doi:10.1001/jamapsychiatry.2018.0544

Lyon, C., Brown, S. W., Van Laar, W. G. M., \& Robertson, R. D. (2019). Road safety monitor 2019: drinking attitudes and practices in Canada. Ottawa: Traffic Injury Research Foundation.

Manthey, J., Shield, K. D., Rylett, M., Hasan, O. S. M., Probst, C., \& Rehm, J. (2019). Global alcohol exposure between 1990 and 2017 and forecasts until 2030: a modelling study. Lancet, 393(10190), 2493-2502. doi:10.1016/S0140-6736(18)32744-2

National Academies of Sciences \& Engineering \& Medicine, Health Medicine Division, Board on Population Health and Public Health Practice, \& Committee on the Review of the Health Effects of Electronic Nicotine Delivery Systems. (2018). In D. L. Eaton, L. Y. Kwan, \& K. Stratton (Eds.), Public Health Consequences of ECigarettes. Washington (DC): National Academies Press (US).

Physicians for a Smoke-Free Canada. (2019). Canadian government revenues from tobacco taxes: An update. Retrieved from http://smoke-freecanada.blogspot.com/2019/12/canadian-governmentrevenues-from.html.

Probst, C., \& Rehm, J. (2018). Alcohol use, opioid overdose and socioeconomic status in Canada: A threat to life expectancy? Canadian Medical Association Journal, 190(44), E1294-1295.

Public Health Agency Canada. (2016). The Chief Public Health Officer's Report on the State of Public Health in Canada 2015: Alcohol Consumption in Canada. Retrieved from https://www.canada.ca/content/dam/canada/healthcanada/migration/healthycanadians/publications/department-ministere/statepublic-health-alcohol-2015-etat-sante-publiquealcool/alt/state-phac-alcohol-2015-etat-aspc-alcooleng.pdf
Public Health Agency Canada. (2018a). The Chief Public Health Officer's Report on the State of Public Health in Canada 2018: Preventing Problematic Substance Use in Youth. Retrieved from https://www.canada.ca/en/publichealth/corporate/publications/chief-public-healthofficer-reports-state-public-health-canada/2018preventing-problematic-substance-use-youth.html

Public Health Agency Canada. (2018b). Measuring the impact of the opioid overdose epidemic on life expectancy at birth in Canada. Retrieved from https://www.canada.ca/en/health-

canada/services/substance-use/problematicprescription-drug-use/opioids/data-surveillanceresearch/harms-deaths/measuring-impact-on-lifeexpectancy.html

Public Health Agency Canada (Producer). (2019, 06/25/2019). National Report: Apparent Opioid-related Deaths in Canada (June 2019). Retrieved from https://health-infobase.canada.ca/datalab/nationalsurveillance-opioid-mortality.html

Rehm, J. (2020). Alcohol use is a key factor in recent decreases in life expectancy in the United States. Alcohol Clinical and Experimental Research, 44(2), 404-406. doi:10.1111/acer.14274

Rehm, J., Anderson, P., Fischer, B., Gual, A., \& Room, R. (2016). Policy implications of marked reversals of population life expectancy caused by substance use. BMC Medicine, 14, 42. doi:10.1186/s12916-016-0590-x

Rehm, J., Gmel Sr, G., Gmel, G., Hasan, O. S. M., Imtiaz, S., Popova, S., . . . Samokhvalov, A. V. (2017). The relationship between different dimensions of alcohol use and the burden of disease - an update. Addiction, 112(6), 968-1001.

Rehm, J., Kilian, C., Ferreira-Borges, C., Jernigan, D., Monteiro, M., Parry, C. D., . . . Manthey, J. (2020). Alcohol use in times of the COVID 19: Implications for monitoring and policy. Drug and Alcohol Review, 39(4), 301-304. doi:10.1111/dar.13074

Rehm, J., Manthey, J., Shield, K. D., \& Ferreira-Borges, C. (2019). Trends in substance use and in the attributable burden of disease and mortality in the WHO European Region, 2010-16. European Journal of Public Health, 29(4), 723-728. doi:10.1093/eurpub/ckz064

Rehm, J., Mathers, C., Popova, S., Thavorncharoensap, M., Teerawattananon, Y., \& Patra, J. (2009). Global burden of disease and injury and economic cost attributable to alcohol use and alcohol use disorders. Lancet, 373(9682), 2223-2233. doi:10.1016/S01406736(09)60746-7

Rehm, J., \& Probst, C. (2018). Decreases of Life Expectancy Despite Decreases in non-communicable disease mortality: The role of substance use and socioeconomic status. European Addiction Research, 24(2), 53-59. Retrieved from http://www.ncbi.nlm.nih.gov/pubmed/29627831

Reid, J. L., Hammond, D., Tariq, U., Burkhalter, R., Rynard, V. L., \& Douglas, O. (2019). Tobacco Use in Canada: Patterns and Trends, 2019 edition. Waterloo, ON: Propel Centre for Population Health Impact, University of Waterloo. 
Shield, K. D., \& Rehm, J. (2019). Alcohol and the global burden of disease. Lancet, 393(10189), 2390. doi:10.1016/S0140-6736(19)30726-3

Special Advisory Committee on the Epidemic of Opioid Overdoses. (2020). Opioid-related harms in Canada. Retrieved from https://healthinfobase.canada.ca/substance-related-harms/opioids

Statistics Canada. (2019). Canadian Tobacco, Alcohol and Drugs Survey (CTADS): Summary of results for 2017. Retrieved from https://www.canada.ca/en/healthcanada/services/canadian-tobacco-alcohol-drugssurvey/2017-summary.html.

Statistics Canada. (2020a). Net income of liquor authorities and government revenue from sale of alcoholic beverages $(x \quad 1,000)$ Retrieved from https://www150.statcan.gc.ca/t1/tbl1/en/tv.action?pid=1 010001201

Statistics Canada. (2020b). Table 13-10-0114-01 Life expectancy and other elements of the life table, Canada, all provinces except Prince Edward Island. Retrieved from https://doi.org/10.25318/1310011401-eng

Tjepkema, M., Wilkins, R., \& Long, A. (2012). Causespecific mortality by education in Canada: a 16-year follow-up study. Health Reports, 23(3), 23-31. Retrieved from http://www.ncbi.nlm.nih.gov/pubmed/23061261

Tjepkema, M., Wilkins, R., \& Long, A. (2013a). Causespecific mortality by income adequacy in Canada: A 16year follow-up study. Health Reports, 24(7), 14-22. Retrieved

from https://www.ncbi.nlm.nih.gov/pubmed/24258280

Tjepkema, M., Wilkins, R., \& Long, A. (2013b). Causespecific mortality by occupational skill level in Canada: a 16-year follow-up study. Chronic Diseases and Injuries in Canada, 33(4), 195-203. Retrieved from http://www.ncbi.nlm.nih.gov/pubmed/23987216

Volkow, N. D. (2020). Collision of the COVID-19 and addiction epidemics. Annals of Internal Medicine, 173(1), 61-62. doi:10.7326/m20-1212\%m 32240293

White, A. M., Castle, I. P., Hingson, R. W., \& Powell, P. A. (2020). Using death certificates to explore changes in alcohol-related mortality in the United States, 1999 to 2017. Alcoholism: Clinical and Experimental Research, 44(1), 178-187 doi:10.1111/acer.14239 